\title{
Viewpoint \\ Obesity hormone leptin: a new target in breast cancer?
}

Eva Surmacz

Sbarro Institute for Cancer Research and Molecular Medicine, Temple University, Philadelphia, PA 19122, USA

Corresponding author: Eva Surmacz, surmacz@temple.edu

Published: 26 January 2007

This article is online at http://breast-cancer-research.com/content/9/1/301

(c) 2007 BioMed Central Ltd
Breast Cancer Research 2007, 9:301 (doi:10.1186/bcr1638)

modulate several processes in the peripheral organs, such as immune response, fertility, and hematopoiesis. On a cellular level, leptin has been found to act as a mitogen, metabolic regulator, and motogenic and pro-angiogenic factors $[1,3]$. In addition, new evidence suggests that leptin could be involved in tumorigenesis, especially in the development of breast, colorectal and prostate cancers [1].

In several breast cancer cell models, leptin has been shown to induce proliferation, survival and anchorage-independent growth. These leptin activities are mediated through the long/signaling form of the leptin receptor (ObRL) that, upon leptin binding, can stimulate the Jak/STAT3, ERK1/2, and phosphoinositide 3-kinase pathways as well as induce cyclin D1 expression and retinoblastoma protein hyperphosphorylation $[1,4]$.

In addition to its own effects, leptin crosstalks with other signaling systems in breast cancer cells. For instance, leptinactivated ObRL has been shown to transactivate HER2/neu [5]. Leptin can also increase the expression of vascular endothelial growth factor (VEGF) [1]. Furthermore, leptin is a potent modulator of estrogen receptor (ER) $\alpha$. First, it stimulates aromatase expression and, as a consequence, elevates estrogen levels via increased aromatization of androgens. Next, it can activate ER $\alpha$ and ER $\alpha$-dependent transcription in a ligand-independent manner [6]. Finally, in the presence of the antiestrogen ICl182,780 (Faslodex), leptin stabilizes $\mathrm{ER} \alpha$, interfering with the proteasomeubiquitin pathways of ER $\alpha$ degradation. All these data suggest that high leptin levels might impede different breast cancer therapies, including those targeting ER $\alpha$, HER2/neu or the VEGF receptor.

The relevance of leptin signaling in breast tumorigenesis is reinforced by the fact that the expression of ObR mRNA and protein has been documented in breast cancer biopsies. Most importantly, ObRL as well as other ObR isoforms are

$\mathrm{ER}=$ estrogen receptor; $\mathrm{ObR}=$ leptin receptor; $\mathrm{ObRL}=$ long, signaling isoform of ObRL; VEGF = vascular endothelial growth factor. 
overexpressed in breast cancer in comparison to normal mammary epithelium and benign mammary tumors $[1,7,8]$.

What is the origin of leptin that acts upon breast cancer cells? Until now, the association between circulating leptin levels and breast cancer or breast cancer risk has not been clear. Some authors found that serum leptin was associated with breast cancer regardless of the menopausal status, while others described a negative correlation between leptin and breast cancer in the premenopausal, but not postmenopausal, group [1]. Other reports claimed that circulating leptin is not associated with breast cancer or breast cancer risk in pre- or postmenopausal women [1]. The inconsistent data obtained with systemic leptin as a breast cancer marker could be, at least in part, explained by differences in detection techniques or by differences in sample preparation where some influencing factors, such as food intake and circadian rhythm, were not controlled. Clearly, better-controlled studies are needed to unequivocally establish whether serum leptin is associated with breast cancer etiology.

Regardless of the impact of circulating leptin, recent studies suggest that breast carcinogenesis could be induced by overabundance of locally produced leptin. The analysis of approximately 300 biopsies revealed that, similar to ObR, leptin is overexpressed in breast cancer, while it is absent or expressed at very low levels in normal epithelium or benign tumors $[7,8]$. Moreover, the expression of leptin positively correlated with ObR, suggesting the existence of an autocrine leptin loop $[7,8]$. Why do breast cancer cells overexpress the leptin/ObR system? Our preliminary data suggest that both markers can be induced by high levels of insulin, estrogen or insulin-like growth factor-l, the factors that are increased in obese individuals [7].

Further insight into leptin involvement in mammary carcinogenesis is provided by studies in animal models. Earlier research using rodents suggested increased body weight as a risk factor in the development of both spontaneous and chemically induced mammary tumors [1]. Recent studies using transforming growth factor- $\alpha$ transgenic mice implied that leptin and ObRL might be necessary for the development of mammary tumors [1]. Finally, a recent report by Gonzalez and colleagues [9] provides evidence that leptin contributes to and is required for mammary tumor development in a mouse syngeneic model. Specifically, leptin induced 4T1 tumor cell growth and stimulated the expression of VEGF/ VEGF receptor 2 . These effects were inhibited by pretreatment of animals with leptin receptor antagonists.

Thus, the existing data suggest that the leptin/ObR system is specifically overexpressed in cancer and might be involved in breast tumorigenesis. However, several questions remain unanswered. For instance, despite the fact that leptin expression can be stimulated by obesity-related factors or conditions, the causal link between overall obesity or upper body obesity in humans and leptin expression in breast tumors has not been established. Similarly, the impact of obesity and leptin (systemic and local) on the response to breast cancer therapy is not known. Finally, if the leptin/ObR system proves to be truly involved in breast cancer development and progression, the efficacy of leptin targeting drugs in breast cancer management should be explored.

\section{Competing interests}

The author declares that they have no competing interests.

\section{Acknowledgements}

Several relevant papers could not be cited due to strict space limitations.

\section{References}

1. Garofalo C, Surmacz E: Leptin and cancer. J Cell Physiol 2006, 207:12-22.

2. Porter GA, Inglis KM, Wood LA, Veugelers PJ: Effect of obesity on presentation of breast cancer. Ann Surg Oncol 2006, 13: 327-332.

3. Hu X, Juneja SC, Maihle NJ, Cleary MP: Leptin - a growth factor in normal and malignant breast cells and for normal mammary gland development. J Natl Cancer Inst 2002, 94: 1704-1711.

4. Frankenberry KA, Skinner $H$, Somasundar $P$, McFadden DW, Vona-Davis LC: Leptin receptor expression and cell signaling in breast cancer. Int J Oncol 2006, 28:985-993.

5. Eisenberg A, Biener E, Charlier M, Krishnan RV, Djiane J, Herman $B$, Gertler A: Transactivation of erbB2 by short and long isoforms of leptin receptors. FEBS Lett 2004, 565:139-142.

6. Catalano S, Mauro L, Marsico S, Giordano C, Rizza P, Rago V, Montanaro D, Maggiolini M, Panno ML, Ando S: Leptin induces, via ERK1/ERK2 signal, functional activation of estrogen receptor alpha in MCF-7 cells. J Biol Chem 2004, 279:1990819915.

7. Garofalo C, Koda M, Cascio S, Sulkowska M, Kanczuga-Koda L, Golaszewska J, Russo A, Sulkowski S, Surmacz E: Increased expression of leptin and the leptin receptor as a marker of breast cancer progression: possible role of obesity-related stimuli. Clin Cancer Res 2006, 12:1447-1453.

8. Ishikawa M, Kitayama J, Nagawa H: Enhanced expression of leptin and leptin receptor (OB-R) in human breast cancer. Clin Cancer Res 2004, 10:4325-4331.

9. Gonzalez RR, Cherfils S, Escobar M, Yoo JH, Carino C, Styer AK, Sullivan BT, Sakamoto H, Olawaiye A, Serikawa T, et al.: Leptin signaling promotes the growth of mammary tumors and increases the expression of vascular endothelial growth factor (VEGF) and its receptor type two (VEGF-R2). J Biol Chem 2006, 281:26320-26328. 